\title{
A promoção da saúde na educação infantil
}

Fernanda Denardin Gonçalves ${ }^{1}$

Ana Maria Fontenele Catrib ${ }^{2}$

Neiva Francenely Cunha Vieira ${ }^{3}$

Luiza Jane Eyre de Souza Vieira ${ }^{4}$

GONÇALVES, F.D. et al. Health promotion in primary school. Interface - Comunic., Saúde, Educ., v.12, n.24, p.181-92, jan./mar. 2008.

The aim of this study was to describe the health promotion work developed by a primary school, in which health promotion principles were incorporated into its pedagogical practices, by investigating six subjects who experienced the process. The realities were verified by means of semi-structured interviews and observation. The following empirical categories emerged from the discourse: 1. care as a health-promoting element; 2. formation of hygienic habits based on education; 3 . health promotion through the pedagogic approach of projects; and 4. establishment of links between health professionals and students. It was concluded that there was a need to carry out systematic training work with educators and health professions, so that the importance of putting integrated health education practices into effect within the various school activity settings is understood.

Key words: Schoolchildren's health. Primary education. Health promotion.
O objetivo do trabalho foi descrever o trabalho de promoção da saúde desenvolvido por uma escola de educação infantil que incorpora princípios de promoção da saúde em sua prática pedagógica, investigando seis sujeitos que vivenciaram o processo. A aproximação da realidade deu-se por meio de entrevista semi-estruturada e observação, emergindo categorias empíricas dos discursos, revelando: 1. o cuidado como elemento promotor de saúde; 2 . formação de hábitos higiênicos com base na educação; 3. promoção da saúde por meio da pedagogia de projetos, e 4 . estabelecimento de vínculo entre profissionais de saúde e alunos. Concluiu-se pela necessidade de se realizar um trabalho sistemático de formação com pedagogos e profissionais de saúde, para que compreendam a importância da efetivação de uma prática interligada e presente da educação em saúde nos diversos âmbitos de atuação da escola.

Palavras-chave: Saúde escolar. Educação infantil. Promoção da saúde.

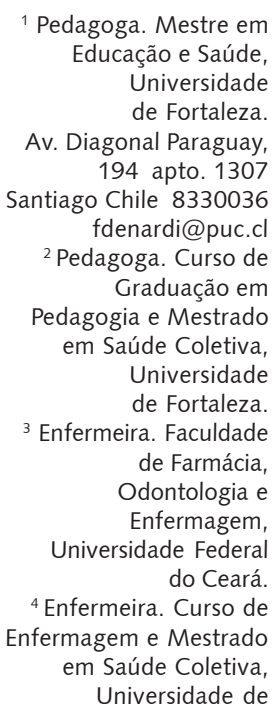




\section{A promoção da saúde na escola: uma breve retrospectiva histórica}

No espaço escolar, o saber teórico e prático sobre saúde e doença foi sendo construído de acordo com o cenário ideológico da época e as questões sobre saúde abordadas com base no referencial teórico de cada momento.

Segundo a Organização Pan-americana de Saúde - OPS (1995), a promoção da saúde no âmbito escolar parte de uma visão integral e multidisciplinar do ser humano, que considera as pessoas em seu contexto familiar, comunitário, social e ambiental. Assim, as ações de promoção de saúde visam desenvolver conhecimentos, habilidades e destrezas para o autocuidado da saúde e a prevenção das condutas de risco em todas as oportunidades educativas; bem como fomentar uma análise sobre os valores, as condutas, condições sociais e os estilos de vida dos próprios sujeitos envolvidos (Pelicioni \& Torres, 1999). Porém, nem sempre essa visão esteve presente nas práticas pedagógicas desenvolvidas nas escolas.

Durante algum tempo, a educação em saúde na escola centrou sua ação nas individualidades, tentando mudar comportamentos e atitudes sem, muitas vezes, considerar as inúmeras influências provenientes da realidade em que as crianças estavam inseridas. Era comum acontecerem ações isoladas voltadas ao trabalho para saúde, partindo de uma visão assistencialista de educação e sem discutir a conscientização acerca do tema saúde e suas inter-relações para o equilíbrio dinâmico da vida (Pelicioni \& Torres, 1999).

Neste contexto, em 1954, a Comissão de Especialistas em Educação em Saúde da Organização Mundial da Saúde - OMS colocou a necessidade de serem realizadas, dentro do espaço escolar, diversas atividades que favorecessem a promoção da saúde, e não somente o trabalho de transmissão de conhecimentos sobre aspectos relacionados à saúde. Nesse sentido, foi apresentada uma abordagem inicial ao conceito de Escola Promotora de Saúde (OMS, 1954).

Também na XIV Conferência Mundial em Educação em Saúde elaborou-se um documento no qual se colocava que todos os locais onde a educação fosse desenvolvida seriam espaços ideais para as aplicações das sugestões básicas da Declaração de Alma Ata e da Carta de Ottawa (Brasil, 2001). Portanto, essas discussões já preconizavam a idéia de que a promoção da saúde consiste em proporcionar à população as condições necessárias para melhorar e exercer o controle sobre sua saúde, envolvendo: paz, educação, moradia, alimentação, renda, ecossistema estável, justiça social e eqüidade.

Após a $4^{a}$ Conferência, em Jacarta, elaborou-se um documento denominado Declaração das Escolas Promotoras de Saúde, o qual preconizava que toda criança tem o direito e deve ter a oportunidade de ser educada em uma Escola Promotora de Saúde (Brasil, 2001).

A Declaração de Bogotá propõe, entre outros, a criação de condições adequadas para a construção do conhecimento que, apoiado pela participação da comunidade educativa, poderá favorecer a adoção de estilos de vida saudáveis e condutas de proteção ao meio ambiente (Brasil, 2001).

Em meio a esses diversos encontros internacionais sobre o tema, onde se refletiu e se explicitou claramente a sua importância, o processo de valorização da promoção da saúde no âmbito escolar também começou a ser percebido no Brasil.

Até 1996, por resolução da Lei de Diretrizes e Bases da Educação Nacional (LDBEN) 5692, o tema saúde era abordado dentro do referencial curricular escolar, utilizando como designação a referência Programas de Saúde, sem ser incorporado como disciplina curricular, e sim como um trabalho a ser desenvolvido de modo pragmático e contínuo (Brasil, 1996a).

O objetivo desse trabalho, segundo o parecer CFE n' 2.264/74, era levar "a criança e o adolescente ao desenvolvimento de hábitos saudáveis quanto à higiene pessoal, à alimentação, à prática esportiva, ao trabalho e ao lazer, permitindo-lhes a sua utilização imediata no sentido de preservar a saúde pessoal e a dos outros" (Brasil, 1996a, p. 43).

Já com a nova LDBEN 9394 e a construção dos Parâmetros Curriculares Nacionais, a saúde no campo da educação passou a ser considerada como um tema transversal, expondo a necessidade de se assegurar uma ação integrada e intencional entre os campos da educação e saúde, uma vez que ambos se pautam, fundamentalmente, nos princípios de formação da consciência crítica e no protagonismo social (Brasil, 1997a, 1996b). 
Os Parâmetros Curriculares Nacionais, dentro do capítulo relacionado ao tema transversal saúde, sugerem que toda escola deve incorporar os princípios de promoção da saúde indicados pela OMS, com os objetivos de fomentar a saúde e o aprendizado em todos os momentos; integrar profissionais de saúde, educação, pais, alunos e membros da comunidade, no esforço de transformar a escola em um ambiente saudável; implementar práticas que respeitem o bem-estar e a dignidade individuais e implementar políticas que garantam o bem-estar individual e coletivo, oferecendo oportunidades de crescimento e desenvolvimento em um ambiente saudável, com a participação dos setores da saúde e educação, família e comunidade. Assim, o desenvolvimento do trabalho com as Escolas Promotoras de Saúde, que já era um movimento internacional, começa a ter força também no Brasil (Brasil, 1997a).

Colaborando com essa idéia, em 1998, o Ministério da Saúde, por meio da Secretaria de Políticas de Saúde, instituiu o Projeto Promoção da Saúde, objetivando elaborar e desenvolver uma política nacional de promoção da saúde. Para o desenvolvimento do seu plano de ação, foram previstas as seguintes linhas de atuação: Promoção da Saúde da Família e da Comunidade, Promoção de Ações contra a violência, Capacitação de Recursos Humanos para a promoção e Escola Promotora de Saúde, Espaços Saudáveis e Comunicação e Mobilização Social (Brasil, 1998).

Com essa dupla preocupação ministerial, o tema da promoção da saúde na escola torna-se um eixo de importante trabalho em nível nacional, deixando clara a visão de que a escola é um espaço de ensino-aprendizagem, convivência e crescimento importante, no qual se adquirem valores fundamentais. A escola é o lugar ideal para se desenvolverem programas da Promoção e Educação em Saúde de amplo alcance e repercussão, já que exerce uma grande influência sobre seus alunos nas etapas formativas e mais importantes de suas vidas.

Ademais, com a LDBEN 9394, as creches e pré-escolas, que atendem crianças de até seis anos, se vincularam ao sistema educacional, abrindo espaço para uma preocupação mais formal com esse nível de ensino, preocupação esta que pode ser identificada também por meio da criação dos Referenciais Curriculares Nacionais da Educação Infantil (Brasil, 1997b).

Este material, mesmo sem explicitar claramente a necessidade do trabalho com a promoção da saúde, expõe a importância do trabalho com a formação integral das crianças. Centra-se nos eixos de Formação Pessoal e Social (incorporando a preocupação com o cuidado infantil dentro do eixo de Identidade e Autonomia) e Conhecimento de Mundo (incorporando o trabalho com conteúdos informativos sobre o tema saúde dentro do eixo de Natureza e Sociedade).

Também a UNICEF e a UNESCO, juntamente com a Organização para Cooperação e Desenvolvimento Econômico e o Ministério de Saúde, publicaram algumas considerações identificando a importância da realização de um trabalho interligado entre os âmbitos da saúde e da educação na primeira infância, como estratégia essencial para a melhoria da qualidade de vida das crianças (UNESCO, 2002; UNICEF, 2001).

Este trabalho apóia-se em pressupostos teóricos que se fundamentam em concepções e visões de mundo sustentadas por diversos saberes, cujas bases repousam nos princípios humanísticos e sociais.

Dessa forma, a saúde no espaço escolar é concebida como um ambiente de vida da comunidade em que está inserida a escola, cujo referencial para ação deve ser o desenvolvimento do educando, como expressão de saúde, com base em uma prática pedagógica participativa, tendo como abordagem metodológica a educação em saúde transformadora (Catrib et al., 2003).

Assim, postulamos o argumento de que as práticas sociais de educação e saúde no contexto escolar devem observar: (i) o reforço do sujeito social para capacitá-lo a cuidar de si e agir em grupo e em defesa da promoção da saúde; (ii) a valorização da subjetividade e intersubjetividade no processo de conhecimento da realidade, privilegiando o diálogo como expressão da comunicação; (iii) o estímulo à participação como algo inerente ao viver coletivo; (iv) a utilização de estratégias que permitam a coexistência da interface de várias áreas do conhecimento; $(v)$ o reconhecimento da dimensão afetiva no processo de transformação e tomada de decisão, e (vi) o incentivo e fomento de parcerias por meio de redes sociais de apoio (Catrib et al., 2003). Esses princípios advogam a adoção de práticas educativas no espaço escolar, criando um clima prazeroso para aprendizagem e vivência de valores humanos.

Diante do exposto, a pesquisa teve o objetivo de descrever o trabalho de promoção da saúde 
desenvolvido por uma escola de educação infantil que incorpora princípios de promoção da saúde em sua prática pedagógica, com base na explicitação de elementos considerados, pelos atores envolvidos, como de fundamental importância nesse processo.

\section{Percurso metodológico}

Com abordagem qualitativa, este estudo descritivo foi realizado em uma escola de Educação Infantil, em Fortaleza, Ceará, no período de 2002 e 2003. A escola pesquisada foi escolhida por buscar a promoção da saúde, uma vez que era composta por uma equipe multidisciplinar, atendendo aproximadamente 140 crianças de dois a seis anos, que pemaneciam em tempo integral (manhã e tarde) no ambiente escolar. Apesar de ser uma escola particular, contava em grande parte com o apoio financeiro do Tribunal de Justiça do Ceará, o que garantia mais recursos para a implantação e real efetivação das práticas necessárias à promoção da saúde.

Como técnica de coleta de dados, utilizou-se a entrevista semi-estruturada com profissionais das duas equipes de trabalho da escola: a equipe pedagógica (Coordenadora Pedagógica e Supervisora Pedagógica) e a equipe do Núcleo de Saúde (Nutricionista, Fonoaudióloga, Psicóloga, Médica e Estagiária de Enfermagem). Participaram do estudo seis profissionais e uma estudante de graduação, profissionais do quadro permanente da escola, todas do sexo feminino e demonstrando muita dedicação ao trabalho desenvolvido nas equipes multiprofissionais.

Com base na transcrição, leitura e análise das entrevistas, norteando-se pela análise de conteúdo (Bardin, 1977), identificaram-se categorias que emergiram das falas das entrevistadas, representando, assim, os elementos considerados, pelos atores envolvidos como de fundamental importância neste processo: 1) o cuidar como elemento presente no trabalho de promoção da saúde na Educação Infantil; 2) a importância da formação de hábitos de higiene por meio do trabalho educativo; 3) promoção da saúde na escola por meio da Pedagogia de Projetos, e 4) a relação afetiva entre os profissionais de saúde e alunos, como elemento de sustentação para o trabalho com a promoção da saúde na escola.

\section{Apresentação e análise dos dados}

Em relação à saúde do aluno e à educação em saúde, o papel da escola centra-se na preocupação com a construção da consciência crítica de seus alunos e, conseqüentemente, com a conquista da cidadania. Nesta perspectiva, as práticas educativas no espaço escolar devem integrar estratégias pedagógicas que propiciem discussão, problematização, reflexão das conseqüências das escolhas no plano individual e social e decisão para agir (Catrib et al., 2003).

Nessa linha de raciocínio, a escola pesquisada constitui-se um espaço com potencialidades de facilitar a promoção da saúde. Conseqüentemente, está em consonância com os princípios humanísticos e sociais, citados anteriormente, contribuindo para a formação de estilo de vida favorável à saúde, pautado no respeito ao bem-estar físico, social e mental da criança, que envolve, também, seus direitos e deveres.

A escola é mantida pelo Poder Público do Estado do Ceará, e voltada ao atendimento dos filhos dos funcionários do Fórum Estadual, localizando-se no entorno deste, o que possibilita aos pais acompanharem as atividades dos filhos, facilitando a adaptação das crianças e a manutenção do vínculo afetivo, bem como o fortalecimento das relações entre família, criança e escola. O horário de funcionamento corresponde ao horário de trabalho estabelecido pela instituição onde os pais trabalham, e os professores e profissionais da escola têm seu vínculo trabalhista formalizado com o Fórum.

Conta com estrutura física adequada, salas amplas e arejadas e espaços adequados à clientela. Atende crianças de creche e pré-escola e contrata seus profissionais, por meio de seleção rigorosa, preparando-os para atuarem na construção de ambiente educacional saudável que promova a saúde. 
Diante dos resultados, o cuidado foi considerado, pelas participantes, como elemento presente no trabalho de promoção da saúde na educação infantil. Nesse sentido, Mello (2000) pontua que cuidar também é educar. Acrescenta-se que, no cuidado, se exerce uma prática educativa, e, com base nesse enfoque, é pertinente considerar todas as áreas que envolvem práticas do cuidado infantil para que sejam integradas ao objetivo educativo. Muitas vezes, quando não conseguimos trabalhar cuidado e educação de forma integrada, acabamos reduzindo e negligenciando as áreas de cuidado como secundárias, na estrutura educacional.

Em relação a essa perspectiva da prática do cuidar, uma das entrevistadas coloca: "[...] a escola aqui é mais voltada para o cuidar. Nós somos uma creche escola [...]" (Membro 3 da Equipe Pedagógica).

Corroborando essa concepção, estudo realizado pela Unesco (2002) pressupõe que "educação e cuidado" são conceitos inseparáveis, e que devem ser necessariamente levados em consideração na educação pré-escolar, devido à sua importância para o desenvolvimento emocional infantil.

Ademais, quando essa profissional foi indagada sobre o que é esse cuidar efetivamente, acrescentou que, entre outras coisas, o cuidado é "fazer com que a criança que entra com um ano e três meses, saia com seis, sendo capaz de fazer a sua higiene pessoal e sabendo se vestir". Outra profissional da equipe também ilustrou a visão de cuidado, que se faz presente na instituição de ensino, como as falas evidenciam:

[...] todas as crianças aqui recebem esse cuidado, todas as crianças aqui vão tirar bico, por exemplo. Aqui na creche é feita essa retirada, já que quase todos chegam chupando bico, como uma prevenção de arcada dentária futura. A gente também tira fralda descartável. Eles chegam aqui usando e a gente espera que, em 4 meses, eles já saibam utilizar o banheirinho. Tem a escovação direcionada, eles aprendem a colocar a pasta na escova diariamente.

(Membro 2 da Equipe Pedagógica)

Como afirma Guimarães (2000), quando se pensa no trabalho com higiene dentro da Educação Infantil, vem a imagem do cuidado como um momento de construção de hábitos e que se deve favorecer a autonomia da criança, pois quando as crianças se trocam sozinhas, algumas regras já são trabalhadas. Dentro desta concepção, o trabalho de formação de hábitos de higiene, realizado com crianças pequenas, deve ter um caráter totalmente pedagógico e não assistencial.

Esse trabalho consegue atingir um âmbito muito mais amplo, que não é unicamente a reprodução de uma necessidade imposta por um adulto, e sim a vivência do trabalho com o corpo e o cuidado e atenção para com ele, mediante o trabalho interligado com regras e limites, fundamental para o desenvolvimento de todo indivíduo. Outros profissionais da escola, quando indagados sobre como acontece o trabalho com a higiene pessoal das crianças dentro da escola, colocaram que:

Por exemplo, tem uma música que passa no Castelo Rá-tim-bum sobre higiene. A gente botou, as meninas fizeram a coreografia e as crianças assimilaram muito nessa hora. Depois a gente passou de sala em sala, perguntando se as crianças entenderam e o que elas entenderam daquilo aqui. (Membro 4 do Núcleo de Saúde)

[...] essa parte de higiene acontece sim, mas é mais a parte da médica. Ela passa a orientação e toda a escola vê. (Membro 1 da Equipe Pedagógica)

Com base na contraposição de tais depoimentos, chama a atenção o fato de um profissional da equipe pedagógica da escola atribuir esse aspecto do trabalho ao "setor médico", negando assim, de certa forma, a visão pedagógica do mesmo. Em contrapartida, a equipe de saúde também vem assumindo para si esse papel, atuando com propostas diversas.

O próprio Núcleo de Saúde é responsável por desenvolver várias atividades que trabalhem temas relacionados às áreas específicas sobre a aquisição de hábitos saudáveis e sua relação com a aquisição e manutenção da saúde. Durante as entrevistas, foram citados vários deles, bem como as propostas 
que estavam relacionadas a eles, podendo-se destacar os projetos: "A higiene na infância", "Água como fonte de vida e saúde", "Alimentação saudável", "É hora de reciclar", "Escovação",

"Mastigação", "Meu dente de leite", "Prevenção de acidentes na infância" (Parte I, II e III), "Quem ouve bem, aprende melhor", "Sabia que o lixo tem seu lugar?" e "Vamos acabar com essa fera!", entre outros.

Todos os integrantes da escola se referiram a esses "projetos" passando a idéia de que a escola utiliza a Pedagogia de Projetos como referencial de proposta metodológica. Atualmente, as escolas, sobretudo as que atendem as crianças na faixa etária da Educação Infantil, têm se colocado como seguidoras de tal corrente, acreditando, assim, na concepção de conhecimento globalizado, que é baseado na descoberta espontânea dos alunos e em uma aprendizagem significativa (Hernandez \& Ventura, 1998).

Como afirma o Membro 5 do Núcleo de Saúde: “Nós procuramos estar sempre desenvolvendo projetos engajados, todos engajados com a proposta pedagógica que temos".

Embora alguns profissionais já tenham clara a visão da importância de tais projetos estarem relacionados à proposta curricular da escola, alguns deles se posicionam dizendo que nem conhecem a mesma. "Em relação a essa questão da escola a gente não está muito a par de como é que a escola trabalha isso é lá com a parte pedagógica" (Membro 5 do Núcleo de Saúde).

Também completa essa idéia o Membro 4 do Núcleo de Saúde:

[...] na verdade a gente não sabe muito como é a proposta curricular da escola, se é usado o construtivismo. Quando tem treinamento e vêm profissionais de fora, em janeiro, a gente vai também. Então assiste: o que é o construtivismo, então tem toda aquela história e a gente está lá. Mas elas aproveitam muito mais do que a gente. E a gente fica vendo que isso não tem nada a ver comigo, entendeu. Mas na verdade a gente fica com dificuldade porque não sabe muito bem o que é.

Essa metodologia de projetos está presente na realidade da instituição do estudo e tem sido vivenciada por professores e alunos. Pelo que foi possível observar, os profissionais de saúde desenvolvem os trabalhos acerca do que, no entendimento destes, é importante ser assimilado pelas crianças, sem se preocuparem em relacionar a situação vivenciada à estrutura curricular.

O trabalho desenvolvido por eles, porém, demonstra ter grande relevância entre as crianças, pois é muito comum vê-las chamando os profissionais de saúde pelo nome e, também, procurando por eles para resolver alguma situação, o que demonstra que está sendo construída uma parceria educativa na promoção da saúde na escola.

Na realização das entrevistas, presenciaram-se crianças entrando na sala do Núcleo de Saúde com muita naturalidade para tirar dúvidas, pedir materiais, ou até mesmo só para cumprimentar os profissionais, afirmando que estavam com saudade.

Durante um depoimento, foi colocado um trabalho de grande valia para essa relação de confiança entre as crianças e as profissionais de saúde, conforme relata o membro 3 do núcleo de Saúde:

As crianças foram ver o núcleo de saúde. Eles foram conhecer todos os profissionais de lá. Gravando, sabe. Então eles foram lá e gravaram: o que é que você faz? Daí eu expliquei tudinho. Oi tia, a gente pode entrar? Pode. No final eles diziam, tchau tia, obrigado. Daí eles iam lá na nutrição. Conheceram todo mundo.

Tal depoimento explicita a importância da relação afetiva entre o profissional de saúde e o aluno, pois quando a escola possibilita a liberdade para que as próprias crianças possam conhecer as pessoas que lá trabalham, possam saber quais são suas atribuições e funções, ela favorece a relação com esses profissionais. Esta estratégia é fundamental para a prática pedagógica, pois não existe aprendizado sem vínculo afetivo. Outro fator de relevância para a construção deste vínculo é o fato de que, nas dependências da escola, os profissionais da área de saúde não usam o "jaleco branco", culturalmente associado com doença e procedimentos dolorosos. 
A literatura retrata que as crianças produzem em seu imaginário conceitos específicos para cada vivência presenciada. Assim, quando se fala em escola, logo se imagina um espaço com várias salas de aula, compostas por mesas e carteiras, professores e alunos. O mesmo acontece com a criança. Quando se fala em hospital, naturalmente ela imagina: médico e enfermeira de branco, pessoas doentes e, até mesmo, injeção e dor. Essa não é a idéia que a escola pesquisada quer que seus alunos tenham do trabalho de saúde.

Nela, nenhum profissional da saúde veste-se de branco e nem reproduz a dinâmica de trabalho de um centro de saúde. Lá se trabalha com educação, com educação em saúde.

Então tem também a questão que você pode acabar confundindo a criança. Ali é um lugar de educação, ou um lugar de tratamento? Eu vou ser a tia ou eu vou ser a doutora? Por isso que a gente não gosta de usar essa roupa branca. No começo a gente usava. Ficava o setor todo de branco, mas as crianças não vinham. Agora a gente trocou essa bata por uma laranja. (Membro 4 do núcleo de Saúde)

Retomando a questão da inserção de projetos relacionados à área de saúde na proposta curricular da escola, é de fundamental importância conhecer os temas que são abordados e que estão intimamente ligados a aspectos de educação em saúde. Tais temas foram detectados pelas pesquisadoras pela análise do material descritivo que a escola possui. Percebeu-se que os temas têm uma dupla função: além de serem trabalhados com as crianças, também devem ser trabalhados com os pais, para que esses adquiram informações novas sobre o tema, conheçam o trabalho da escola e reforcem esse tipo de ação pedagógica em casa.

Ao se realizar um paralelo entre os materiais escritos apresentados pela escola e as entrevistas realizadas, percebe-se que os temas citados foram unicamente aqueles nos quais houve uma integração maior entre os demais profissionais da escola, pais e alunos. Percebe-se então que os temas que ficaram marcados para os educadores foram os vivenciados por eles e pelas crianças, em parceria com a família.

Sabe-se que a criança até os seis anos é ainda um ser muito concreto, que não formou a noção de abstração. Justamente por isso a prática pedagógica das escolas de Educação Infantil deve estar pautada na vivência experimental dos conteúdos a serem trabalhados. Somente o que for vivenciado será apreendido, o que não for, será esquecido. Nesta perspectiva, vale citar, de forma sucinta, o trabalho realizado com os quatro projetos indicados nas entrevistas como os de maior êxito.

\title{
Projeto Vamos acabar com essa fera
}

\author{
Uma equipe da Edisca fez um teatro sobre piolho. Elas fizeram uma paródia, uma campanha \\ dos caça-piolho, porque a gente não estava conseguindo acabar com a pediculose através \\ dos pais. As crianças entraram de férias com o intuito de chegar aqui sem piolho. (Membro 5 \\ da Equipe Pedagógica)
}

O desenvolvimento do projeto relacionado à eliminação da pediculose dentro da escola aconteceu de forma bem presente e participativa. Todos os entrevistados, em algum momento, relembraram tal trabalho e o êxito por ele alcançado. Para o desenvolvimento do mesmo, houve a participação ativa das crianças, que viram peças de teatro, aprenderam paródias de músicas relacionadas a esse tema e tornaram-se os próprios caçadores de piolhos, com direito a carteirinha e broche de super-herói.

Com toda essa parte lúdica envolvida na metodologia a ser trabalhada, as crianças realmente voltaram de férias sem piolhos, e não por uma insistência dos pais, mas sim porque, como diz o Membro 3 da Equipe Pedagógica, "era a criança que não queria mais ter piolho". Brincando, a criança entra no mundo do imaginário, onde ela é autora do seu próprio comportamento, aprendendo a dominar regras, trabalhar suas emoções e seus medos (Penteado, Seabra, Pereira, 1996). Um dos pontos fortes para o grande sucesso desse projeto foi a inserção do lúdico dentro do trabalho pedagógico. Com isso, as crianças se envolveram nas propostas e formaram o hábito do cuidado consigo e com o próprio corpo. 
Outro ponto foi a integração dos dois núcleos, fazendo com que tanto os profissionais de saúde quanto os profissionais pedagógicos estivessem envolvidos nesse trabalho, como afirma o Membro 2 da Equipe Pedagógica:

Pra mim a maior integração foi nesse projeto. É que tinha pai reclamando, a gente vendo a situação e tinha que fazer alguma coisa. Então na reunião surgiu a idéia e a gente foi fazendo. As aulas eram planejadas a partir do tema, com histórias e tudo mais. E eles adoraram ser os super-heróis caçadores de piolho. Se você perguntar até hoje eles lembram.

\section{Projeto Alimentação saudável}

Quando você falar com a nutricionista você vai ver, como é a preocupação aqui. Tem criança que nunca tinha comido fruta, nem verdura, e aí a criança aprende a gostar. Vão bandejões de fruta pras salas. Tem kiwi, tem uva, tem melancia. [...] E a nutricionista fez tudo isso sozinha e conseguiu muita criança comendo fruta, porque a gente apóia, mas ainda é pouco. (Membro 2 da Equipe Pedagógica)

Segundo Halpern (2003), a obesidade infantil é um sério problema de saúde pública que vem aumentando em todas as camadas sociais da população brasileira. Preveni-la significa diminuir, de forma racional e barata, a incidência de doenças crônico-degenerativas, como o diabetes e as doenças cardiovasculares, e um grande palco para a realização deste trabalho é a escola, que pode possibilitar a educação nutricional, juntamente com a família. Assim, a alimentação saudável é hoje um conteúdo educativo e a incorporação desses hábitos pode dar-se na infância. É justamente por isso que pais e educadores vêm, ao longo de anos, concordando com a necessidade de a escola assumir um papel de protagonismo nesse trabalho.

Nessa escola, tal preocupação é presente por meio da atuação da nutricionista. Além de preparar o cardápio dos alunos, ela também acompanha o momento de alimentação, reforçando o consumo de frutas e verduras, trabalha a experimentação de novos alimentos em sala de aula e faz um acompanhamento direto com os pais de alguns alunos.

Com todo esse trabalho, ela vem identificando mudanças gratificantes:

Olha, o trabalho é grande, mas vale a pena [...] tem muita mãe que chega pra mim e diz que está conseguindo mudar muita coisa em casa, agradece meu trabalho e diz que a reunião serviu muito pra ela também ir mudando as coisas em casa [...] porque eu não posso trabalhar sozinha, preciso da família e aí consigo muita coisa. (Membro 1 do Núcleo de Saúde)

\section{Projeto relacionado à fala}

A gente do núcleo de saúde fez, por exemplo, um projeto de fala. Demos uma luva pra cada criança e a gente falava, fala RA. Daí a gente falava, você está falando certo? Olha no espelho. Aí a criança olhava. Aí a gente tocava pra sentir onde é que a lingüinha bate. Em alguns esse trabalho fica, mas em outros tem que ser um trabalho continuado. Mas o nosso papel é ir incentivando a criança. Eles falam: tia, aprendi a falar RATO, mas na outra palavra já voltou ao normal. Mas ele viu que ele pode aprender. Ele tem consciência que a língua é nesse canto. Da próxima vez vamos trabalhar voz. Então já estamos preparando o boliche, cartaz. Então a gente passa o mês inteiro só falando daquele tema. (Membro 2 do Núcleo de Saúde)

Segundo os Conselhos Regionais de Fonoaudiologia, é de competência do fonoaudiólogo desenvolver trabalho de prevenção no que se refere à área da comunicação oral e escrita, voz e audição e, também, participar da equipe de orientação e planejamento escolar, inserindo aspectos preventivos ligados a assuntos fonoaudiológicos. Na escola investigada, a intervenção fonoaudiológica é uma prática presente 
que aparenta colher bons frutos. O trabalho é pautado na idéia de que os alunos são responsáveis pelo seu aprendizado e, para que ele ocorra, é necessário que o sujeito entenda os processos que o favorecem.

Quando um profissional coloca à disposição da criança um material que ela nunca tem acesso, como é o caso da luva médica, ele já cria o interesse necessário para impulsionar o processo de aprendizagem. Quando a criança percebe que ela mesma pode cuidar de si própria para melhorar algo que não está bem, ela busca a transformação da realidade singular dela mesma.

Esse projeto foi muito citado nas entrevistas, evidenciando a atuação da fonoaudióloga dentro da escola, mas identificando também que não existe um trabalho de integração para que a proposta tenha uma continuidade na rotina diária das crianças, sendo desenvolvido também pelas professoras.

Isso está bem evidenciado, por exemplo, no seguinte comentário: “Esse projeto foi um dos melhores [...] as crianças estavam muito envolvidas e a fono sabe bem como envolvê-las com essas coisas que só ela mesmo pra fazer com as crianças" (Membro 1 do Núcleo Pedagógico).

\section{Projeto Mastigação}

Existem projetos maiores, como o da mastigação. Porque tinha muita criança mastigando errado. Esse é um trabalho que a fono faz junto com a nutrição. [...] Foi um trabalho com teatro, fantoche, tudo isso a gente fez. Todo mundo foi comer na frente da tia. Então a gente foi passando de criança em criança pra ver se estavam mastigando certo. Tudo isso as professoras fazem. Então, você vê que é um trabalho que deu resultado. O projeto foi um sucesso! (Membro 2 do Núcleo de Saúde)

O Projeto Mastigação surgiu com base na observação das duas profissionais da área de saúde que trabalham diretamente com essa questão: a fonoaudióloga e a nutricionista. Apesar de não ter surgido das crianças, vários profissionais afirmam que o projeto foi um sucesso. E por que isso aconteceu? Que fatores contribuíram? É possível pensar que o fator fundamental para o seu bom desenvolvimento foi a metodologia utilizada. Trabalhos com teatro, contar histórias, faz de conta, tudo isso faz parte do imaginário infantil e é de extremo interesse para as crianças.

Como coloca Jones (1996, p.114):

[...] a história alimenta a emoção e a imaginação. Permite a auto-identificação, ajuda a criança a aceitar situações desagradáveis e a resolver conflitos. Através do jogo do faz de conta, a criança procura compreender como as coisas se dão de forma cognitiva e afetiva, além de se apropriar das vivências e as internalizar, tornando-as suas.

Ademais, outro ponto foi fundamental nesse trabalho: a participação dos professores, já que, por orientação dos profissionais de saúde, começaram a ficar atentas à mastigação dos alunos, bem como, também, desenvolver atividades pedagógicas sobre o tema, como explicita o Membro 2 do Núcleo Pedagógico: "Essa coisa da mastigação virou moda. Todo mundo trabalhou. Foi impressionante. Não foi só o pessoal da saúde, também a gente estava querendo ajudar. No fim, todo mundo estava de olho na mastigação".

Este, como os demais projetos pedagógicos apresentados, mostra como acontece a atuação dos profissionais de saúde dentro da prática pedagógica. O trabalho principal é baseado em projetos de estudo, onde vários aspectos relacionados à saúde são abordados. Assim, como os próprios profissionais trabalham esses aspectos com os grupos de crianças, também trabalham individualmente com cada um, e ainda orientam os professores para que continuem a realizar tal proposta.

Esses projetos são consistentes e pautados em conceitos que reforçam o aprendizado. McGinnis \& Degraw (1991) pontuam que o conhecimento, as atitudes, os comportamentos e as habilidades desenvolvidos em efetivos programas de saúde em escolas, voltados para a conscientização de que a adoção de hábitos saudáveis trará melhor qualidade de vida, capacita crianças e jovens para fazerem 
escolhas corretas sobre comportamentos. Reforçam que a adoção desses comportamentos promove a saúde do indivíduo, da família e da comunidade, por meio de um trabalho que deve se iniciar na primeira infância.

\section{Conclusão}

Conforme relatado, é possível ressaltar a validade da iniciativa dos educadores da escola pesquisada em trabalhar com a promoção da saúde nesse espaço. Ao entrevistar os profissionais, é facilmente identificável a real presença do trabalho de promoção da saúde na escola. Assim, vale apresentar esta iniciativa para que, primeiramente, se possa demonstrar que a realização desse trabalho é possível e, com base nessa realidade, explicitar aspectos que poderiam facilitar a reprodução da experiência.

Nesse sentido, a literatura enfatiza que a escola é um ambiente propício para a aplicação de programas de educação em saúde, pois a mesma está inserida em todas as dimensões do aprendizado (Fernandes, Rocha, Souza, 2005).

Mas existe um aspecto importante a ser considerado como um ponto de reflexão. Este aspecto está relacionado com a auto-responsabilização da equipe de saúde pelo trabalho desenvolvido. Com base nos relatos apresentados e, sobretudo, quando são descritos aspectos específicos da prática diária (a exemplo dos projetos de trabalho com as crianças), identifica-se que a práxis com o tema saúde, na maioria das vezes, está a cargo unicamente dos profissionais desta área, fazendo com que o trabalho seja realizado de forma pontual e isolada.

Assim, faz-se necessária uma maior integração do trabalho desses profissionais com a equipe pedagógica. Davanço, Taddei e Gaglianone (2004) afirmam que os representantes da equipe pedagógica, e, sobretudo, o professor, devem ser incorporados como membros centrais da equipe de saúde escolar, pois além de possuírem uma similaridade comunicativa com seus alunos, têm maior contato com eles e estão envolvidos na realidade social e cultural de cada discente, aspectos estes que facilitam o trabalho.

Desta forma, um desafio a se considerar é a necessidade de uma revisão das propostas curriculares dos centros de formação de educadores em saúde, sejam eles profissionais de saúde ou da educação. Tal medida objetiva a incorporação, nos diversos cursos, de um trabalho de conscientização sobre a importância do desenvolvimento compartido de atividades que envolvam os temas transversais, bem como um trabalho de orientação metodológica para o desenvolvimento desta proposta.

Nessa linha de pensamento, encontra-se a necessidade de se promoverem espaços que favoreçam a troca de experiências tanto entre os profissionais integrantes da área pedagógica, para que possam dar continuidade e implementar novos trabalhos relacionados com o tema saúde, quanto entre os profissionais do núcleo de saúde, para que assimilem elementos ainda mais pedagógicos e adequados a cada faixa etária.

Leonello \& L'Abbate (2006) enfatizam a necessidade de se olhar para o educador. Acrescentam que não desconsideram a importância da atuação e integração da equipe de saúde na escola; ao contrário, a escola, como equipamento social, deve interagir e articular estratégias de promoção à saúde com essa equipe.

Barba, Martinez e Carrasco (2003) defendem que uma visão intersetorial poderá se constituir em um caminho, quando se objetiva a promoção da saúde e educação de crianças no Brasil. Saúde, educação e desenvolvimento são conceitos que não podem caminhar sozinhos.

Finalizando, educação em saúde, na concepção das autoras, vai além de ações pedagógicas para garantia de serviços de saúde. Antes de tudo, é o desenvolvimento de possibilidades geradoras de mudanças pessoais e sociais, promovendo sentido à vida. 


\section{Colaboradores}

Os autores Fernanda Denardin Gonçalves, Ana Maria Fontenele Catrib, Neiva Francenely Cunha Vieira e Luiza Jane Eyre de Souza Vieira participaram, igualmente, de todas as etapas de elaboração do artigo.

\section{Referências}

BARBA, P.; MARTINEZ, C.; CARRASCO, B. Promoção da saúde e educação infantil: caminhos para o desenvolvimento. 2003. Disponível em: <http://sites.ffclrp.usp.br/ paidea/artigos/26/01>. Acesso em: 20 jul. 2006.

BARDIN, L. Análise do conteúdo. Lisboa: Edições 7, 1977.

BRASIL. IEC/FIOCRUZ. Promoção da saúde. Declaração de Alma-Ata. Carta de Ottawa. Declaração de Adelaide. Declaração de Sundsvall. Declaração de Santafé de Bogotá. Declaração de Jacarta. Rede de Megapaíses. Declaração do México. Brasília: Ministério da Saúde, 2001.

BRASIL. Ministério da Educação e do Desporto. Secretaria da Educação Fundamental. Referenciais Curriculares Nacionais para a Educação Infantil. Brasília, 1997a.

. Parâmetros Curriculares Nacionais. Brasília, 1997b.

Lei de Diretrizes e Bases da Educação Nacional n 5692. Brasília, 1996a.

Lei de Diretrizes e Bases da Educação Nacional no 9394. Brasília, 1996b.

BRASIL. Ministério da Saúde. Secretaria de Políticas de Saúde. Promoção da saúde: 1998. Disponível em: <http:// www.saude.gov.br/sps>. Acesso em: 20 jul. 2006.

CATRIB, A.M.F. et al. Saúde no espaço escolar. In: BARROSO, M.G.T.; VIEIRA, N.F.C.; VARELA, Z.M.V. (Orgs.). Educação em saúde no contexto da promoção humana. Fortaleza: Edições Demócrito Rocha, 2003.

DAVANÇO, G.M.; TADDEI, J.A.A.C.; GAGLIANONE, C.P. Conhecimentos, atitudes e práticas de professores de ciclo básico, expostos e não expostos a curso de educação nutricional. Rev. Nutr., v.17, n.2, p.177-84, 2004.

FERNANDES, M.H.; ROCHA, V.M.; SOUZA, D.B. A concepção sobre saúde do escolar entre professores do ensino fundamental (1 ${ }^{\mathrm{a}}$ a $4^{\mathrm{a}}$ séries). 2005. Disponível em: <http://www. scielo.br/scielo.php?pid=S0104-59702005000200004\&script $=$ sci arttext>. Acesso em: 20 jul. 2006.

GUIMARÃES, L. Os fazeres na educação infantil. São Paulo: Carochinha, 2000.

HALPERN, Z. Fórum nacional sobre promoção da alimentação saudável e prevenção da obesidade na idade escolar. 2003. Disponível em: <http://www.abeso.org.br/ revista/ revista15/forum.htm>. Acesso em: 20 jul. 2006.

HERNANDEZ, F.; VENTURA, M. A organização do currículo por projetos de trabalho. Porto Alegre: Art Med, 1998.

JONES, I. La imaginación, punto de partida de las escuelas. Rev. Org. Mundial Salud, v.49, n.4, p.111-39, 1996. 
LEONELLO, V. M.; L'ABBATE, S. Educação em saúde na escola: uma abordagem do currículo e da percepção de alunos de graduação em Pedagogia. Interface - Comunic., Saúde, Educ., v.10, n.19, p.149-66, 2006.

MCGINNIS, J.; DEGRAW, C. Healthy Schools 2000: creating partnerships for the decade. J. Sch. Health, v.61, n.7, p.192-7, 1991.

MELLO, A. Um diálogo com os diretores de creches e pré-escolas. In: GUIMARÃES, L. (Org.). Os fazeres na Educação Infantil. São Paulo: Carochinha, 2000. p.21-49.

OMS. ORGANIZAÇÃO MUNDIAL DE SAÚDE. Comissão de Especialistas em Educação em Saúde da Organização Mundial da Saúde. Washington: OMS, 1954.

OPS. ORGANIZAÇÃO PANAMERICANA DE SAÚDE. Educación para la salud: un enfoque integral. Washington: OPS, 1995. (Série HSS/SILOS, n. 37).

PELICIONI, C. A escola promotora de saúde. São Paulo: Faculdade de Saúde Pública da Universidade de São Paulo, 1999. p.12. (Séries Monográficas)

PENTEADO, R.; SEABRA, M.; PEREIRA, I. Ações educativas em saúde da criança: o brincar enquanto recurso para participação da família. Rev. Bras. Crescimento Desenvolv. Hum., v.6, n.1/2, p.49-56, 1996.

UNESCO. Organização para a cooperação econômica e o desenvolvimento. Ministério da Saúde. Educação e cuidado na primeira infância: grandes desafios. Brasília: Unicef, 2002.

UNICEF. Situação da infância brasileira. Brasília: UNICEF, 2001.

GONÇALVES, F.D. et al. La promoción de la salud en la educación infantil. Interface - Comunic., Saúde, Educ., v.12, n.24, p.181-92, jan./mar. 2008.

Con el objetivo de describir una práctica pedagógica promotora de la salud en una escuela de educación infantil que incorpora estos principios en su cotidiano, se desarrolló un trabajo cualitativo, con seis sujetos que vivenciaron este proceso. La aproximación a la realidad se hizo por medio de entrevista semi-estructurada y observación, emergiendo categorías empíricas de las declaraciones, revelando: 1. el cuidado como elemento promotor de la salud; 2 . formación de hábitos higiénicos a partir de la educación; 3. promoción de la salud a través de la pedagogía de proyectos y 4. establecimiento de vínculos entre profesionales de salud y alumnos. Se concluye en este estudio la necesidad de realizar un trabajo sistemático de formación con pedagogos y profesionales de salud, para que estos puedan comprender la importancia de la realización de una práctica interconectada y presente de la educación en salud en los diversos ámbitos de actuación de la escuela.

Palabras clave: Salud escolar. Educación infantil. Promoción de la salud. 